\title{
Study on the Development and Evolution of Digital Content Industry and Strategic Countermeasures
}

\author{
Taking Japan as an Example
}

\author{
Jialin Jin \\ Sichuan University of Media and Communications \\ Chengdu, China 611745
}

\author{
Jiaxin Zhu \\ Sichuan University of Media and Communications \\ Chengdu, China 611745
}

\begin{abstract}
As the impact of economic globalization and international cultural trend, the digital content industry has become a national culture one of pillar industries, especially in Europe, America, Japan, Korea and other countries in the world development. In this essay, based on the digital content industry of Japan Asia developed countries in the development of speech and its strategic resolution of all, then contrast and tease out the digital content industry development status quo of China's problems, the last of the benign development of the China digital content industry put forward feasible suggestions.
\end{abstract}

Keywords-digital content industry; Japan; reform; promotion strategy

\section{INTRODUCTION}

In recent years, with the development of Internet, crossborder integration and scientific and technological innovation, digital content industry has become an important force to promote steady economic growth. China digital content industry in recent years a rapid development momentum, but also faced with planning and measures, policy and management, high quality content and lack of talent, and so on questions, restricts the development of China digital content industry. This article through to Japanese digital content industry in the developed countries in-depth research and analysis, summarize tease out Japan developed countries in the industry of construction and its strategic layout, construction of the development of China's digital content industry to provide useful reference and enlightenment.

\section{DEVELOPMENT OF DIGITAL CONTENT INDUSTRY}

\section{A. The Connotation and Definition of Digital Content Industry}

What is the digital content industry? Each country has a different definition. In the definition of Digital Content Industry in Japan, the first comes from the English Content Industry, as the loan words in Japanese language, Japanese translation for Content Industry, therefore, now of the Digital Content Industry, Digital Content Industry is translated into Japanese Digital content industry. Japan is widely accepted "the content industry", the concept of digital content industry from the content industry, is along with the development of digital technology and the content change of industrial structure and derived a new pattern of industry. [1]Content industry in Japan, international strategy research report of the content industry has made the following definition: the socalled content industry, is the ability to bring the spirit of the people (heart) enjoy "information", can be to operate economic' property." [2]According to Japanese meti white paper(2016)published the latest digital content industry According to the newly published digital content industry white paper (2016) of Japan's the latest digital content industry to industry categories, including: images, music, (sound), games, publishing, Internet advertising and mobile advertising, books, newspapers and magazines, books, newspapers, pictures, magazines, etc. a few broad categories.

In 2009, the white paper on China's digital content industry, the digital content industry is defined as: "relying on the information infrastructure and all kinds of information product marketing channels, to provide customers with the digital images, characters, images, voice, and other products and services industry type." It is recommended to divide into eight categories: online game, digital animation, digital publishing, digital learning mobile content, digital audiovisual, other network services and content software.[3]

\section{B. The Development of Digital Content Industry in Japan}

Statistical data in 2005, for example, the scale of content industry all over the world for 146 trillion yen (about 8.598 trillion yuan), among them, 60 trillion yen (about 3.5334 trillion yuan) in the United States, Europe, 47.4 trillion yen (about 2.7914 trillion yuan), Japan, the largest proportion of the domestic market size of 13.8 trillion yen (about 812.7 billion yuan) [4].From 2009 to 2016,Japan's digital content industry market scale and output value experienced a rapid development--a sharp decline--a sharp rise in a large scale of output value. In the end, it is a leading development strategy for Japan to turn the digital content industry into reverse economic decadence and revitalize the Japanese economy. In terms of data, Japan's digital content industry has also surpassed the traditional Japanese automobile manufacturing industry. The author also released for the Japanese economy, trade and industry (meti) within the digital content industry (2009-2016), the white paper data calculated combing: 2009 Japan's content industry market size of 12.1563 trillion yen (about 716.4 billion renminbi), 2010 of 1.2641 trillion yen 
(about 710.9 billion yuan), $0.77 \%$ less than the previous year. In 2011 , it was 124.6 billion yen ( 710.3 billion yuan), down $0.08 \%$ from the previous year. In 2012, it was 11894 bn yen (about 7000.9 billion yuan), down $1.32 \%$ from the previous year. In 2013, it reached 119,04bn yen (701.5 billion yuan), an increase of $0.09 \%$ over the previous year. In 2014, it reached 1274.8 billion yen (711.6 billion yuan), an increase of $1.44 \%$ over the previous year. In 2015, it reached 125,0500 million yen ( 710.6 billion yuan), down $0.14 \%$ from the previous year. In $2016,123,929$ billion yen ( 730.3 billion yuan) was up 2.77 percent from the previous year. From the perspective of data, from 2009 to 2012, the scale of Japanese digital content market showed a relatively decreasing trend, and the market size began to increase continuously from 2013.

For 2009 to 2012, the digital content industry in Japan, in has been the cause of the decline is: first, the rest of the world in the digital content industry is in rapid development, greatly enhance the international competitiveness, especially the rapid development of China's criterion more show a strong development potential; Second, Japan was in second place in the global economy around 2009, but the Japanese economy has been in a slump. At this time, the global financial crisis broke out, and the Japanese economy was once again hit hard, which directly affected the development of domestic digital content industry. Third, Japan also faces the problem of aging population and young children, leading to a shrinking population. It is obviously very difficult to use the content industry to drive domestic demand. Fourth is Japan's political instability and multi-party conflict. In the three years from 2009 to 2012 , Japan's prime minister was replaced by three prime ministers, a frequent change that has affected the implementation of the digital content industry's development and development strategy. To sum up, at this stage of the Japanese government has been a constant adjustment of industrial structure and deepen the reform of the contents, use a variety of policies to support and promote, but still to improve to a level with the order of magnitude more difficult.

Between 2012 and 2016, Japan's digital content market became active due to the relatively stable political situation in Japan, and the market size was on the rise. From 2012 to 2017, the prime minister has been appointed by shinzo Abe. Japan's political stability has played a very positive role in Japan's economic development. Especially, starting in 2012, Japan continue to deepen reform, formulate long-term "new growth strategy", upgrade to specific strategic planning, unified organization and coordination, and in such aspects as financial support and personnel training to do a lot of support and input, prompted the Japanese digital content industry get rapid development in these few years.

\section{JAPAN'S STRATEGY FOR THE DEVELOPMENT OF DIGITAL CONTENT INDUSTRY}

\section{A. Information Communication Network Construction Stage--Popularization and Application of Internet (2001-2005)}

In 2001, the Japanese prime minister junichiro koizumi to the Japanese government has carried on the largest reform after the war, the national government ministries and agencies to conduct a comprehensive integration, especially for the department of information and communication ministry of posts and telecommunications and province, precisely to merge, set up the communications ministry. The Japanese government has set up the "high information communication network promotion strategy department", which is directly held by the prime minister. At the third reform conference, the government formulated the e-japan strategy as an IT country strategy and guided the implementation of the e-japan key plan.

The "e-japan strategy" focuses on four major aspects. First, the construction of ultra-high-speed Internet. Within 5 years, we have built a common ultra-high-speed network (30 $\sim 100 \mathrm{Mbps}$ ) and reached the highest level in the world. Low fees, let the whole people share; Second, the promotion of ecommerce. By 2002, the reform of e-commerce development and regulation was completed, and the legal system of ecommerce contract rules and consumer protection policies was established, which increased the popularity of ecommerce. Third, the realization of electronic government. By 2003, the state and local regions had implemented electronic intelligence to promote social IT. Fourth, talent cultivation strengthens. By 2005, specialized training and quality enhancement for IT technologists, IT guidance personnel, researchers, etc.

Practical results: of the target of "e - Japan strategy", given the effective implementation and fall to the ground, the Internet enjoy plan prompted the 30 million households using high-speed network, about 10 million households enjoy the ultra high speed network. Meanwhile, Japan has the lowest rates of Internet access in the world. As of late 2005 , the Japanese Internet penetration rate is as high as $66.8 \%$, to the mobile phone and other mobile Internet utilization rate is $57 \%$, which is mobile Internet users, using the computer for the first time exceeded the number of users on the Internet. At the same time, the number of broadband users on the Internet.At the same time, the number of broadband users reached about 23.3 million. In this way, the goal of the "e-Japan strategy" proposed by Japan is realized.[5]

\section{B. The Formation Stage of Network Communication Society -- The Internet and Digitization Are Fully Popularized (2006-2009)}

In the strategy of "e - Japan" planning goals are completed, in 2006, Japan launched a new reform strategy "IT", namely: in 2010, took the lead in the world to complete, mutual sharing of sustainable development of the IT network 
society. That is to say, let the Japanese people freely enjoy the Internet to live and work.

The focus of "IT new reform strategy" focuses on three aspects: first, to give full play to the structural reform of IT and solve the existing problems in Japanese society; Second, support IT structure transformation force, improve the whole network society's foundation; Third, making Japanese voices to the world and contributing to the international community. [6]

During this period of reform and construction, Japan, like other countries, experienced the financial turmoil of 2008, which made it worse for Japan. This also prompted the government to discuss immediately, and make the start for long-term development of a new strategy in 2015, define the name of the "I - Japan strategy", concrete is called "digital strategy of a new era -- three years of emergency plan". The main core of the strategy focuses on the breakthrough of digital technology, which integrates the development of digital technology and information technology, so as to generate new vitality for the Japanese economy. Then, within the government, the LDP lost the election to the DPJ, which was run by the DPJ. The differences in governing philosophy also make some changes in the implementation of the new strategy, and the results are not perfect. However, during the unstable Japanese political situation, the network and digitization of Japanese society have been widely popularized.

\section{The New Era of Digital Media Network(2010-2017)}

In 2009, the cabinet meeting of the new Japanese government adopted the "new growth strategy". In June 2010, the new regime cabinet meeting to "new growth strategy" development planning, and plan in 2020 to achieve "strong strong strong economic, finance, social security integration goals, and in the process of implementation of the" new growth strategy ", and built seven grand strategy, the implementation of the strategy is the focus of the strategy of "science, technology, information communication state".

In 2013, as Japan's prime minister, shinzo Abe, and with foreign so-called "economics" Abe to review all Japan, strengthen the strategic planning and overall layout, to develop a fruitful new growth strategy, strategy of "Japan xing" (Japan is Back), make Japan a country in the world, the first IT. The strategic content is mainly to carry out the regulation and system reform thoroughly, and improve the foundation of information communication, security and talents. Open and electronic administrative services for public data; Create IT safe and convenient living environment; Once again the communication infrastructure is upgraded; Resetting of network security countermeasures; Training and guarantee of high-level IT personnel.[7]

\section{PRoblems Existing IN THE DEVELOPMENT OF DigitAL CONTENT INDUSTRY IN CHINA}

Political and economic environment is the important macro factor affecting the development of industrial market [8].For China, digital content industry is an emerging high value-added industries, started later than other countries, but along with China's rapid economic growth, China's digital content market size and growth rate, has a certain scale, and develop rapidly. Although China's digital content industry has been included in the 11th five-year plan for cultural construction and the long-term plan for 2020. It clearly points out that it encourages the development of digital content industry and actively develops the information service industry. However, China's digital content industry should be continuously and steadily developing, and there are many problems to be solved.

\section{A. Lack of Specific Strategic Planning and Measures}

China's digital content industry covers a wide range of fields, and the regional characteristics are different, which is not profound enough for the development of digital content industry. The Chinese government has promoted the development of the digital content industry as guidance and Suggestions, and fundamentally lacks strategic industrial policies, specific plans, implementation steps and safeguards.

\section{B. Lack of Sound Support Policies and Management of Parallel Crossings}

China digital content industry management control is still in the multilateral management, management functions mainly scattered in the ministry of culture, the general administration of press and publication, general administration of industry and information technology, radio and television, and other national departments, overall management and policy coordination difficulty is very big, appear even administrative monopoly. Overall management and policy coordination difficulty is very big, appear even administrative monopoly[9].Therefore, the management system is not centralized, the support policy coordination is insufficient, and the unfair competition will hinder the development of the industry. Due to the management of parallel overlapping problems, the duplication of the digital content industry platform bases has resulted in the uneven quality of content products and the lack of market recognition.

\section{Lack of High-level Digital Content Technology and Management Personnel}

Innovation is a powerful weapon to enhance competitiveness at present. For the development of digital content industry, innovation is the focus of competition. However, the high speed development of digital content industry requires a high degree of innovation and creativity. This kind of high innovation requires a lot of knowledge reserve and intellectual input, and relies on a lot of high level and creative talents. , therefore, the cultivation of the talent is the key to the development of digital content industry, In turn, the severe shortage of talents is bound to affect and restrict the sustainable of digital content.[10] The development of digital content industry in China is relatively backward in terms of creative talents, technical talents and operation and management talents. The main reasons for this are: first, policy and institutional reasons. The slow change of system, coupled with the lack of implementation, delayed the development of enterprises and lowered the expectations 
of talents. Second, low remuneration and unfair distribution of remuneration are difficult to attract and retain senior talents. Third, the development opportunity and the development space problem causes the brain drain serious.

\section{Lack of Sound Intellectual Property Rights and Digital Rights Protection Mechanism}

China is still weak in legal environment issues such as intellectual property rights and digital copyright protection, and there are many loopholes and inadequacies. As far as industrial development is concerned, the technology and content of output are not protected by strong law, which is bound to affect the benign development of the digital content industry chain. Cause the protection mechanism problems are: first, the transmission of digital content industry market environment is poorer, difficult to crack down on piracy, cost is high, especially in China's software, audio and video in the spread of Internet copyright issue is very outstanding; Second, because of inadequate strength of the joint law enforcement between multiple departments, law enforcement cooperation degree owed to the tacit understanding, the law enforcement division of labor is not clear, in the process of handling copyright disputes, accrual coordination mechanisms can be a problem; Third, China to the relative lack of copyright protection consciousness of the masses, for piracy behavior enterprise insufficient knowledge and the harm to the society, relevant departments of the professional level of copyright professionals is the phenomenon of existence and time not neat; Fourth, social non-governmental organizations (agencies) are underdeveloped, lacking certain expertise, knowledge, standardization, self-discipline and integrity.

\section{CONCLUSION}

Based on the analysis of Japanese digital content white paper (2001-2016), we can see the cause of the rapid development of digital content industry in Japan. Although China's digital content industry is developing rapidly, the structure of industrial development is unbalanced, and it is concentrated in individual cities, such as Beijing and Chengdu. However, in the development stage of China's digital content industry, there are problems such as lack of unified coordination management, specific unclear strategic planning, and lack of high-level talents. Therefore, in order to further strengthen the overall planning, scientificity and feasibility of industrial development, and formulate a comprehensive promotion strategy in line with China's reality, the author puts forward the following Suggestions:

\section{A. Change of Importance -- Establish an Authoritative Digital Content Industry Department with Centralized Management Functions}

It is easy to see from the development of Japan's digital content industry that Japan's digital content industry has reached the world's leading position, which is closely related to its continuous strategic reform and upgrading. One of the most significant decision strategy is Japan's multiple functions for great integration, establish the communications ministry, implementation of the whole Japan's overall planning, decision-making, implementation, and formed an effective reform of the system. For China, still can draw lessons from the Japanese model, in the digital content industry to establish a set of overall planning, overall coordination and overall planning execution authority government departments or agencies, thus forming a topdown management level. Implementation and implementation of policies conducive to industrial objectives. At this time, we should strengthen cooperation management, make overall planning, integrate business, and subdivide guidance and norms for all industries.

\section{B. Necessity Regulation -- Establishment and Related Laws and Regulations}

Both in Europe and the United States and in the Asian countries, the rapid development of industry is combined with the perfect legal system. Digital technology, media industry, cultural industry and other aspects need to be integrated with perfect laws and regulations. The development of China digital content industry, must be to integrate the existing laws and regulations, cleaning, adjustment, combined repetitive laws and regulations, revoke the unreasonable, unnecessary laws and regulations, to add supplementary vacancy of laws and regulations. To strengthen the perfection of the intellectual property law "and other laws and regulations as well as the revision, reasonable and effective of the digital content industry specific and standardization and legalization, output value with safety protection for digital content.

\section{Feasibility Strategy -- The State Should Strengthen the Construction of Personnel Training and Attracting Talents}

The main competitive force of digital content industry is technology and innovation competition, which will also be reflected in the competition of talents. At present, there is a shortage of outstanding talents with innovative spirit, specialization, operation, diversification and international vision in digital content industry. In this, to accelerate hightech innovative technology talented person's raise, relying on domestic and foreign universities, research institutes and other resources, fast high quality talented person to cultivate a large number of digital content industry, let the talent structure and the demand to achieve balanced, sustainable development can make the digital content industry. In addition, domestic enterprises should be for talents reasonably adjust the welfare treatment, the respect such as living environment conditions, let the senior talents, steady development effectively help other practitioners in technology, ideas, improvement of management, so as to use of talent effectiveness to support industrial development.

\section{Promoting Sexual Transformation -- Combining Traditional Cultural Innovation and Development, and Taking the Special Digital Path}

In the digital age, traditional Chinese culture is also important in the integration and innovation. It is a new opportunity and challenge to combine traditional culture and innovation development. To promote the traditional culture 
and the transformation of digital convergence, the author provides some Suggestions: first, to have strong government organization to do guarantee, the use of the government information resources, to coordinate different departments make a comprehensive plan as a whole, industry information resource integration, for example: for the city of Shanghai industry informatization construction, unified decisionmaking, planning, implementation and other functions, to Shanghai in the digital industry and cultural industry has achieved very good results, and is superior to the domestic other cities; Second, set up the traditional culture and sharing platform of digital creativity, the organic integration of traditional culture resources, information resources, crossregional, interdisciplinary cooperation development of digital content industry, speed up domestic development chain digital content industry. For example, with the domestic representative and authoritative depth of traditional art association cooperation, for the traditional ethnic culture cross each other, mutual confluence, the content of new products are derived from the creative content. Third, major engineering projects with large enterprises at home and abroad, the effective integration of cultural resources and digital resources, which is conducive to innovation and output of innovation, promote the traditional culture and the combination of digital content, transformation and upgrading.

\section{E. Inevitability Integration -- Accurately Controlling the Development of Global Digital Content Industry and Going Global}

China digital content industry development cannot be like the frog in well to understand the world digital content industry change situation, thorough combing other countries subdivided market, competition, competitive strategy and so on several aspects, build up the internationalization of China's digital content industry system. In contrast to the government, financial investment and financing should be encouraged to provide a sound financing channel for digital content producers. To learn from foreign advanced the system of the digital content industry and the management pattern, rapid flood into the international digital content industry's development, as far as possible close distance with advanced countries in the world, rapidly expanding international market, the internationalization of digital content industry.

\section{REFERENCES}

[1] Li Jingjing, zhang zhiqiang: comparative analysis of digital content industry in China and Japan [J]. Journal of huaiyin normal university (social science edition), 2011(2):273.

[2] Li haichun, "the current situation and development of Japanese content industry" [J]. Modern communication, 2007(1):112-116.

[3] A white paper on digital content industry in Shanghai in 2009, the Shanghai digital content industry promotion center, http://www.chinadcic.org.cn/article.php? Id = 79 .

[4] Chen hongmei, "from content industry revitalization to content revitalization -- current situation and policy adjustment of Japan's content industry" [J]. Film art, 2008(2):120.

[5] "The 18th edition of the intelligence and communication book [EB/OL]",

http://www.soumu.go.jp/johotsusintokei/whitepaper/index.html。
[6] "The construction of new media and Japanese information society" [J] News lover, 2013(2):29.

[7] The Japanese slightly - JAPAN is BACK again - PDF, affairs province, 2013 (6) : 44.

[8] "The development strategy of China media under the reconstruction of the world communication system" [J]. Media, 2017(12):10 pages.

[9] Han jiping: research on the growth mechanism and development strategy of digital content industry $[\mathrm{J}]$. Doctoral dissertation of jilin university, 2010(12):135.

[10] Zhou zhiping, "problems and development strategies of digital content industry in China" [J]. Reform and strategy, 2014(3):102. 